\title{
Drying by desorption: a tool to determine spray-drying parameters
}

\author{
Pierre $\mathrm{SCHUCK}^{1 *}$, Eric BLANCHARD ${ }^{2}$, Evelyne ONILLON $^{2}$, \\ Anne DOLIVET $^{1}$, Serge MEJEAN ${ }^{1,3}$, Romain JEANTET ${ }^{1}$ \\ ${ }^{1}$ UMR 1253 Science et Technologie du Lait et de l'CEuf, INRA-Agrocampus Rennes, 65 rue de Saint-Brieuc, \\ 35042 Rennes Cedex, France \\ ${ }^{2}$ Laiterie de Montaigu, ZI du planty, 85807 Montaigu, France \\ ${ }^{3}$ Bionov, 85, rue de Saint Brieuc, 35042 Rennes cedex, France
}

*e-mail : pierre.schuck@,rennes.inra.fr

The most frequently used technique for dehydration of dairy products is spray drying. This is an effective method for preserving biological products as it does not involve severe heat treatment and it allows storage of powders at an ambient temperature. Due to the variety and complexity of the concentrates to be dried, a more rigorous understanding of spray-drying based on physico-chemical and thermodynamic properties has now become necessary. At the same time, the current state of the art and knowledge do not allow determination of the parameters of spray-drying of dairy products. The only way to determine these parameters is to perform several complex and expensive experiments with spray-dryer pilots.

The aims of this study were to evaluate the ratio of bound to unbound water by using a method of drying by desorption (Schuck et al., 1998). The results, combined with thermodynamic and physico-chemical parameters (such as absolute and relative humidity of air, total solids and temperature of concentrate, air flow rate, etc.), provide more precise determination of certain spray-drying parameters such as inlet air temperature and mass flow rate. We performed more than 30 experiments to correlate calculated and measured parameters in a pilot plant (Bionov) using water, skim milk, caseinate and maltodextrin. The results show that the difference between the calculated and measured inlet air temperature was below $5 \%$, the determination coefficient being close to 0.96 .

The economic interest of this system is obvious, because it is easy to anticipate the spraydrying parameters by using a controller integrating the water availability of the concentrate and certain thermodynamic parameters. Software based on this step was developed (SD2P ${ }^{\circledR}$, Spray Drying Parameters Simulation \& Determination) and registered at the APP (Association pour la Protection des Programmes).

Schuck P, Roignant M, Brulé G, Davenel A, Famelart MH, Maubois JL (1998) Simulation of water transfer in spray drying. Drying Technology, 16 (7), 1371-1393. 